\title{
Strategi Komunikasi dan Pelayanan Kader Kesehatan terhadap Pencegahan Penyakit Menular pada Komunitas Suku Anak dalam di Kabupaten Batanghari Provinsi Jambi
}

\author{
Listautin $^{1}$, Nia Nurzia ${ }^{2}$ \\ ${ }^{1,2}$ Universitas Adiwangsa Jambi \\ Jl. Sersan Muslim RT 24 Kelurahan Tehok Kebun Kopi Kec. Jambi Selatan \\ Correspondence email : listautin59@gmail.com
}

\begin{abstract}
Abstrak. Indonesia sebagai Negara Tropis merupakan kawasan endemik berbagai penyakit menular, seperti malaria, TBC, ISPA, diare, DBD, penyakit kulit, hepatitis dan sebagainya. Suku anak dalam merupakan nama yang popular di deretan suku yang ada di Indonesia. Mereka memiliki sifat yang tidak dimiliki oleh manusia biasa, tertutup, keras kepala, fanatik terhadap adat yang sudah kuno. Angka penyakit menular suku anak dalam cukup tinggi seperti ISPA menduduki peringkat tertinggi $34 \%$ dari Jumlah penduduk. Malaria $33 \%$ dari jumlah penduduk, penyakit kulit 29,8\% dari Jumlah penduduk. Hepatitis $23 \%$ dari 325 jumlah penduduk. Tujuan penelitian adalah untuk mengetahui pengaruh strategi komunikasi dan pelayanan kader terhadap pencegahan penyakit menular pada suku anak dalam Kabupaten Batanghari. Jenis penelitian ini adalah penelitian analitik dengan pendekatan kuantitatif. Desain penelitian adalah desain quasi eksperimen yaitu Time series design, dengan pengukuran pre test dan post test. Desain penelitian ini hanya menggunakan satu kelompok saja, sehingga tidak memerlukan kelompok control. Populasi penelitian ini adalah seluruh Komunitas Suku Anak Dalam baik laki-laki maupun perempuan dewasa yang berjumlah 325 dengan jumlah sampel 74 responden. Uji hipotesis yang digunakan adalah uji hipotesis komparatif yaitu Uji T berpasangan (wilcoxon). Hasil uji statistik menunjukkan bahwa nilai p-value $<0.005$ yang berati ada perbedaan antara hasil pendidikan strategi komunikasi dan pelayanan kader kesehatan pre test dan post test sehingga dapat di simpulkan bahwa ada pengaruh strategi komunikasi dan pelayanan kader kesehatan terhadap pencegahan penyakit menular. Upaya yang dapat dilakukan adalah selain mengajarkan kader tentang pencegahan penyakit menular, kader perlu di ajarkan secara intens cara komunikasi terapeutik sehingga kader kesehatan lebih mudah memberikan informasi dan memberikan layanan kepada komunitas Suku Anak Dalam.
\end{abstract}

Kata kunci: Komunikasi; Pelayanan Kader; Penyakit Menular

\begin{abstract}
Indonesia as Tropical Country is an endemic area for various infectious diseases, such as malaria, tuberculosis (TBC), Acute Respiratory Infections (ARI), diarrhea, Dengue Hemorrhagic Fever (DHF), skin diseases, hepatitis and so on. One popular tribe in Indonesia, known as Suku Anak Dalam, they haveunique behavior such as closed-minded, stubborn and fanatical about old custom. The number of infectious diseases of SukuAnakDalam is quite high, the highest is ARI about 34\% of total population, malaria is about $33 \%$ of the population, skin disease about $29.8 \%$ of the population, and hepatitis $23 \%$ of 325 population. The purpose of this study is to determine the effect of communication strategies and cadre services toward the prevention of infectious diseases in Suku Anak Dalam Batanghari. This research is analytic research, quantitative approach. The research design is quasi-experimental design using Time series design, pre-test and post-test measurements. The design of this study uses only one group, without control group. The population of this research is Suku Anak Dalam community, either male or female adult with the total number is about 325, and the samplesare 74 respondents. The hypothesis test used is comparative hypothesis test, T-test paired (Wilcoxon). Statistical test results show that p-value $<0.005$ means that there are differences between the educational outcomes of communication strategies and pre-test and post-test of health cadre services. It can be concluded that there is an effect of communication strategies and health cadre services toward the prevention of infectious diseases. The efforts that can be applied such as teaching cadres about the prevention of infectious diseases and intense way of therapeutic communication therefore health cadres can provide information and provide services to Suku Anak Dalam community easily.
\end{abstract}

Keywords: Communication; Cadre Services; Infectious diseases

\section{PENDAHULUAN}

Angka kematian penyakit menular di Indonesia cukup tinggi dan prevalensinya meningkat karena dipengaruhi oleh faktor lingkungan serta perilaku hidup masyarakat (Kemenkes RI, 2016).

Indonesia adalah kawasan endemik dan merupakan negara tropis sehingga berbagai penyakit menular, seperti malaria, TBC, ISPA, diare, DBD, penyakit kulit, hepatitis dan sebagainya lebih banyak di temui. (Achmadi. U.F, 2008).
Masalah yang sering terjadi terutama masalah kesehatan lingkungan di Negara berkembang pada umumnya terdiri dari lima hal yaitu masalah sanitasi (jamban), penyediaan air minum, perumahan (housing), pembuangan sampah, dan pembuangan air limbah (air kotor). (Adnani. H, 2011).

Manusia terkadang menghubungkan terjadinya penyakit dengan keseimbangan alam, dan ada pula yang menghubungkan penyakit dengan alam supranatural. Menurut mereka berbagai penyakit yang 
terjadi disebabkan faktor roh halus misalnya adanya anggapan bahwa penyakit berhubungan dengan perilaku buang hajat di pohon besar yang di huni oleh mahluk halus (Achmadi, U.F 2008).

Di Provinsi Jambi Suku anak dalam merupakan suku yang terkenal di berbagai suku yang ada di Indonesia, mereka memiliki sifat unik yang tidak dimiliki oleh manusia biasa, tertutup, keras kepala, fanatik terhadap adat yang sudah kuno. Mereka terdiri dari kelompok dibawah kepemimpinan temenggung atau kepala suku. Mereka memanfaatkan keteduhan hutan serta seluruh ruang hutan belantara bagi kehidupan (Wahyuni, C.U \& Artanti KD M, 2016).

Komunitas Suku Anak Dalam masih saja tertinggal dalam kehidupannya apalagi di masa perkembangan zaman yang melaju sangat cepat pada saat ini, Mereka masih menikmati dan menjalankan kehidupan sehari-hari seperti yang dilakukan oleh nenek moyang mereka ratusan tahun yang lalu (Wahyuni, C.U \& Artanti KD M, 2016).

Untuk menggapai komunitas suku anak dalam diperlukan strategi khusus agar komunitas bisa percaya terhadap dunia kesehatan dan menikmati pelayanan kesehatan. Kader kesehatan merupakan perpanjangan tangan dari petugas kesehatan. Dengan adanya kader kesehatan, maka pelayanan kesehatan yang selama ini hanya di kerjakan oleh petugas kesehatan saja seperti perawat, bidan maupun dokter, dapat di bantu oleh kader yang berasal dari masyarakat tersebut, kader yang di bentuk telah di latih sehingga memiliki kemampuan dasar dalam menangaini masalah kesehatan yang sifatnya sederhana. Oleh karena itu kader harus dibina, di bimbing, serta di dukung oleh pembimbing yang terampil dan berpengalaman seperti Bidan, perawat, dan tenaga medis maupun non medis lainnya (Wahyuni, C.U \& Artanti KD M, 2016).

Berdasarkan survey pendahuluan yang dilakukan pada 28 Agustus 2018, angka kejadian penyakit menular suku anak dalam cukup tinggi. pada bulan Januari- Juli 2018 seperti penyakit ISPA menduduki peringkat tertinggi 34\% dari Jumlah penduduk. Penyakit Malaria $33 \%$ dari jumlah penduduk, penyakit kulit $29,8 \%$ dari Jumlah penduduk. Hepatitis $23 \%$ dari 325 jumlah penduduk. Berdasarkan survey pendahuluan yaitu wawancara langsung kepada kader, peran kader terhadap komunitas suku anak dalam adalah mendemonstrasikan atau mempraktikkan ilmu yang didapatkan dari pendidikan kesehatan yang telah diberikan oleh tenaga kesehatan kepada komunitas suku anak dalam dan mengumpulkan komunitas jika ada pengobatan gratis dari Puskesmas maupun Dinas Kesehatan Provinsi maupun Kabupaten.

Pendidikan kesehatan yang di berikan kepada kader kesehatan memiliki keterbatasan dari segi penyampaian dikarenakan kurangnya ilmu pengetahuan kader dan karakter komunitas suku anak dalam sulit diberikan pemahaman. Komunitas suku anak dalam lebih percaya dengan kepala suku (ketua adat), dukun dan tumenggung sehingga untuk menyikapi hal tersebut, lembaga Komunitas Konservasi Indonesia (KKI) WARSI Jambi mengajak puskesmas untuk membentuk kader kesehatan yang berasal dari komunitas suku anak dalam tersebut untuk memudahkan komunikasi terhadap komunitas, kader telah di bentuk dan diberikan pelatihan-pelatihan tentang pelayanan kader namun kader mengeluh bahwa komunitas hanya sedikit yang menjalankan apa yang telah diinformasikan oleh kader, dan masih banyak Komunitas yang belum memahami apa yang telah diajarkan oleh kader.

Penelitian ini bertujuan untuk melihat pengaruh strategi komunikasi dan pelayanan kader kesehatan terhadap pencegahan penyakit menular pada suku anak dalam.

\section{METODE}

Jenis penelitian ini merupakan penelitian analitik dengan menggunakan pendekatan kuantitatif. Desain penelitian yang digunakan dalam penelitian ini yaitu quasi eksperimen (Quasi Eksperiment Design) dengan pengukuran pre test dan post test. Peneliti ingin melakukan percobaan yaitu mengetahui pengaruh strategi komunikasi dan strategi pelayanan kader (variabel independen) terhadap pencegahan penyakit menular (variabel dependen) pada Komunitas Suku Anak Dalam.

Desain quasi experiment yang digunakan adalah Time series design. Desain penelitian ini hanya menggunakan satu kelompok saja, sehingga tidak memerlukan kelompok kontrol (Sugiono, 2016).

Lokasi penelitian ini dilaksanakan di Kabupaten Batanghari. Penelitian Pre test dilaksanakan pada tanggal 27 - 28 Juni 2019. Pemberian perlakuan pendidikan kesehatan pada 28 Juni 2019, sedangkan penelitian post test dilaksanakan pada tanggal $21-22$ Agustus 2019. Dalam penelitian ini yang menjadi Populasi adalah seluruh Komunitas Suku Anak Dalam baik laki-laki maupun perempuan dewasa yang berjumlah 325 orang dengan jumlah sampel 74 responden. Penelitian ini menggunakan teknik pengumpulan data dengan cara Tes (Pre test), Perlakuan atau eksperimen semu, observasi, dan tes (post test). Kelompok eksperimen terlebih dahulu diberikan pretest Sebelum diberi perlakuan, kemudian diberi perlakuan (treatment) dengan memberikan pelatihan kepada kader kesehatan tantang strategi komunikasi dan pelayanan kader, setelah itu kader kesehatan yang telah diberikan pelatihan diberikan kesempatan untuk memberikan ilmu yang di dapatkan selama pelatihan tentang komunikasi kepada Komunitas Suku Anak Dalam dan pelayanan kader kesehatan, setelah itu Komunitas Suku Anak Dalam diberikan post test. 
Listautin dan Nia Nurzia, Strategi Komunikasi dan Pelayanan Kader Kesehatan terhadap Pencegahan Penyakit Menular pada Komunitas Suku Anak dalam di Kabupaten Batanghari Provinsi Jambi

Analisis data menggunakan analisis univariat, sedangkan uji hipotesis yang digunakan adalah uji hipotesis komparatif skala pengukuran kategorik (ordinal) dengan 2 kelompok berpasangan yaitu Uji T berpasangan (wilcoxon).

\section{HASIL DAN PEMBAHASAN}

Distribusi Pelayanan Kader Kesehatan dan Pencegahan Penyakit Menular

Berdasarkan hasil penelitian tentang pelayanan kader kesehatan, didapatkan hasil bahwa Pelayanan Kader Kesehatan sebagai berikut:

Tabel 1. Distribusi Pelayanan Kader Kesehatan

\begin{tabular}{lcc}
\hline Pelayanan Kader Kesehatan & Jumlah & Persentase (\%) \\
\hline Kurang Baik & 53 & 71.6 \\
Cukup Baik & 15 & 20.3 \\
Baik Jumlah & 6 & 8.1 \\
\multicolumn{1}{c}{ Jum } & $\mathbf{7 4}$ & $\mathbf{1 0 0 . 0}$ \\
\hline
\end{tabular}

Berdasarkan tabel di atas, didapatkan hasil bahwa pelayanan kader kesehatan kurang baik sebanyak 53 responden $(71.6 \%)$, pelayanan kader kesehatan cukup baik 15 responden $(20.3 \%)$ dan baik sebanyak 46 responden $(8.1 \%)$.

Berdasarkan hasil penelitian, didapatkan hasil bahwa pencegahan penyakit menular sebagai berikut:

Tabel 2. Distribusi Pencegahan Penyakit Menular

\begin{tabular}{lcc}
\hline Pencegahan Penyakit Menular & Jumlah & Persentase (\%) \\
\hline Kurang Baik & 44 & 59.5 \\
Cukup Baik & 23 & 31.1 \\
Baik $\quad 7$ & 9.5 \\
$\quad$ Jumlah & $\mathbf{7 4}$ & $\mathbf{1 0 0 . 0}$ \\
\hline
\end{tabular}

Tabel di atas menunjukan bahwa sebagian besar responden 59,5\% memiliki pengetahuan cara pencegahan penyakit menular kurang baik. 31,1\% responden yang memiliki pengetahuan cara pencegahan penyakit menular dengan kategori cukup baik, dan hanya 9,5\% memiliki pengetahuan cara pencegahan penyakit menular kategori baik.

\section{Pengaruh Strategi Komunikasi dan Pelayanan Kader Kesehatan terhadap Pencegahan Penyakit Menular}

Tabel 3. Gambaran Pencegahan Sebelum dan Sesudah Perlakuan (Pemberian Pendidikan) Strategi Komunikasi dan Pelayanan Kader Kesehatan.

\begin{tabular}{llcc}
\hline Keterangan & Hasil Analisa Paired Sample T Test & \\
Mean & Std. Deviation & P \\
\hline Pre test & 1.50 & 0.667 & 0.000 \\
Post test & 2.14 & 0.669 & \\
\hline
\end{tabular}

Hasil uji Paired Sampel T Test didapatkan hasil bahwa Rerata pre test adalah 1.50 (SD 0.667), sedangkan nilai Rerata post test adalah 2.14 (SD 0.669). Dan pada hasil pre test dan post test, nilai $\mathrm{p}$ sebesar
$0.000<0.05$ maka dapat diberi kesimpulan bahwa terdapat perbedaan yang nyata antara perlakuan pemberian pendidikan strategi komunikasi dan pelayanan kader.

Tabel 4. Hasil Uji Beda Selisih Pencegahan Penyakit Menular Pretest dan Post test

\begin{tabular}{ccccc}
\hline Keterangan & \multicolumn{3}{c}{ Wilcoxon Test } & \multicolumn{1}{c}{$\begin{array}{c}\boldsymbol{P} \\
\text { Value }\end{array}$} \\
\hline Selisih Pencegahan & Mean & Jumlah & $Z$ & \\
Penyakit Menular & Ranks & Ranks & & \\
${$\cline { 2 - 4 }$} }$ & 20.00 & 120.00 & -5.235 & 0.000 \\
Post Tes & 25.70 & 1105.00 & & \\
\hline
\end{tabular}

Pada tabel Pencegahan Penyakit Menular diperoleh hasil Uji bahwa antara pemberian perlakuan pendidikan tentang strategi komunikasi dan pelayanan kader kesehatan untuk pre test dan post test terdapat jumlah 20.00 negative ranks yang berarti bahwa ada 6 hasil post test yang tidak mengalami perubahan pengetahuan pencegahan penyakit menular setelah dilakukannya perlakuan pendidikan strategi komunikasi. Dari uji beda selisih data pada tabel di atas, mayoritas responden mengalami peningkatan terhadap pencegahan penyakit menular pada komunitas suku anak dalam yaitu sebesar 25.70. Dan terdapat nilai ties 25 yang berarti bahwa ada nilai yang sama antara pre test dan nilai post test setelah diberikan perlakuan.

Hail uji statistik diketahui nilai p-value $0.000<$ 0.005 yang berati bahwa hipotesis diterima. Hasil uji pre test dan post test terdapat ada perbedaan antara hasil perlakuan yaitu pemberian pendidikan strategi komunikasi dan pelayanan kader kesehatan. Sehingga dapat di simpulkan bahwa strategi komunikasi dan pelayanan kader kesehatan mempengaruhi terhadap pencegahan penyakit menular.

Hasil uji Paired Sampel T Test bahwa pada penelitian ini terdapat perbedaan yang nyata antara perlakuan pemberian pendidikan strategi komunikasi dan pelayanan kader pada hasil pre test dan post test. Secara statistik penelitian ini terdapat pengaruh yang bermakna antara strategi komunikasi dan pelayanan kader kesehatan terhadap pencegahan penyakit menular.

Penelitian ini di dukung oleh penelitian yang telah dilakukan oleh Wahyuni. C.U \& Artanti. K.D, 2016 yaitu tentang Pelatihan Kader Kesehatan Untuk Penemuan Penderita Suspek Tuberkulosis dengan hasil yaitu terdapat perbedaan bermakna antara pengetahuan tentang TB pada pretest dibandingkan dengan post test (nilai $\mathrm{p}<0,05$ ).

Untuk mencapai suatu tujuan dalam berkomunikasi, strategi komunikasi menjadi paduan dari perencanaan komunikasi (communication planning) dan menejemen komunikasi (Communication Management) (Aslesmana, 2015). Sebagai makhluk sosial manusia senantiasa tentu ingin dapat selalu berhubungan dengan manusia lainnya. Ingin mengetahui lingkungan 
sekitarnya, bahkan ingin mengetahui yang terjadi dalam dirinya. Rasa ingin tahu ini memaksa manusia perlu berkomunikasi. Dalam hidup bermasyarakat, orang yang tidak pernah berkomunikasi dengan orang lain maka terisolasi dari masyarakatnya. Pengaruh keterisolasian ini menimbulkan depresi mental yang pada akhirnya membawa orang kehilangan keseimbangan jiwa (Wahyuni. C.U \& Artanti. K.D, 2016).

Agar menjadi komunikasi yang lebih berkualitas, komunikasi manusia harus direncanakan, diorganisasikan, ditumbuh kembangkan. Salah satu langkah penting yang harus dilakukan adalah menetapkan strategi komunikasi. Strategi komunikasi sangat menentukan sejauh mana kita mengerahkan seluruh kekuatan dan sumber daya demi tercapainya komunikasi (Liliweri. A, 2011).

Pendidikan Strategi komunikasi yang dilakukan dalam penelitian ini menggunakan metode Soler dan metode persuasif. Metode soler yaitu mengajarkan kader untuk berkomunikasi dengan cara peserta duduk secara menglingkar berhadap-hadapan di lahan tempat tinggal komunitas Suku Anak Dalam, dengan posisi tubuh bebas tapi santai. Posisi ini dilakukan dengan tujuan agar terjadi kontak mata dan menggunakan bahasa dan kebiasaan adat budaya yang berlaku. Sedangkan metode persuasif dilakukan karena karakteristik responden dalam klasterisasi atau kategori daerah kumuh dan responden bertempat tinggal di lokasi kebun karet (Liliweri. A, 2011).

Pendidikan strategi komunikasi dilaksanakan dengan beberapa tujuan yaitu Annoucing (memberitahu) adalah memberitahukan tentang kapasitas dan kualitas informasi, informasi yang diberikan sedapat mungkin berkaitan dengan informasi yang dibutuhkan oleh masyarakat. Motivating (Memotifasi) yaitu Informasi yang disebarkan harus dapat memberikan motivasi bagi masyarakat tentang informasi yang disampaikan. Educating (Mendidik) yaitu Informasi yang di sampaikan harus bersifat mendidik yaitu menjelaskan bagaimana cara masyarakat dapat mengaplikasikan informasi yang diberikan. Informing (menyebarkan informasi) yaitu menyebarluaskan informasi kepada masyarakat yang menjadi sasaran dalam berkomunikasi, informasi yang disebarkan merupakan informasi yang spesifik dan actual artinya informasi diberikan secara singkat namun jelas. Mendukung pembuatan keputusan yaitu informasi yang dikumpulkan dikategorisasi di analisis sedemikian rupa, sehingga dapat dijadikan informasi utama bagi pembuatan keputusan (Liliweri. A, 2011),

Hasil penelitian Rusdiyanti, I (2013), mengenai strategi komunikasi menunjukkan uji hipotesis bahwa strategi komunikasi dan petugas askes mempengaruhi tingkat kepuasan pasien pengguna kartu askes di RSUD Djoelham, Binjai dengan nilai Rs 0,165.
Pembentukan kader bertujuan agar kader mampu melaksanakan beberapa kegiatan yang sifatnya kegiatan yang bias dilakukan oleh kader tetapi tetap berguna bagi masyarakat seperti kader dapat melakukan kegiatan seperti pengobatan ringan sederhana yaitu pemberian obat cacing, pengobatan terhadap diare, serta pemberian larutan gula garam, penimbangan, pemberian obatobatan sederhana dan penyuluhan gizi, serta pemberantasan penyakit menular seperti pencarian dan pendataan kasus, pelaporan vaksinasi, pemberian distribusi obat, dan lainnya (Efendi.F \& Makhfudli, 2009).

\section{SIMPULAN}

Ada pengaruh strategi komunikasi dan pelayanan kader kesehatan terhadap pencegahan penyakit menular pada Suku Anak Dalam di Kabupaten Batanghari Provinsi Jambi. Komunikasi manusia harus direncanakan, diorganisasikan, ditumbuh kembangkan agar menjadi komunikasi yang lebih berkualitas. Salah satu langkah penting adalah menetapkan strategi komunikasi. Strategi komunikasi sangat menentukan sejauh mana kita mengerahkan seluruh kekuatan dan sumber daya demi tercapainya komunikasi. Untuk itu di harapkan Puskesmas atau instansi terkait memberikan pendidikan kesehatan secara rutin perihal cara menerapkan komunikasi dan meningkatkan pelayanan kader kesehatan agar Komunitas Suku Anak dalam lebih memahami informasi atau pendidikan maupun pengetahuan yang didapatkan dari pelatihan kader.

\section{DAFTAR PUSTAKA}

Achmadi, U.F. (2008). Manajemen Penyakit Berbasis Wilayah. Jakarta

Achmadi, U.F, (2008), Horison Baru Kesehatan Masyarakat di Indonesia. Rineka Cipta, Jakarta

Adnani. H. (2011). Ilmu Kesehatan Masyarakat. Yogyakarta

Arikunto, S. (2010). Manajemen Penelitian. Jakarta: Rineka Cipta

Aslesmana, 2015. Efektivitas Strategi komunikasi Program KB Melalui Iklan Layanan Masyarakat. Di Unduh Oktober 2018

Dahlan. S. (2011). Statistik untuk Kedokteran dan Kesehatan. Jakarta: Salemba Medika

Effendi. F \& Machmudli. (2009). Keperawatan Kesehatan Komunitas Teori dan Praktik dalam Keperawatan. Jakarta : Salemba Medika

Kemenkes RI, (2016). Profil Kesehatan Indonesia. Jakarta

Kunoli. F.J, (2013). Pengantar epidemiologi Penyakit Menular untuk Mahasiswa Kesehatan Masyarakat.Jakarta

Lameshow. S. dkk. (1997). Besar Sampel dalam Penelitian Kesehatan. Yogyakarta: Gadjah Mada university Press 
Listautin dan Nia Nurzia, Strategi Komunikasi dan Pelayanan Kader Kesehatan terhadap Pencegahan Penyakit Menular pada Komunitas Suku Anak dalam di Kabupaten Batanghari Provinsi Jambi

Liliwery. A. (2011). Komunikasi : Serba Ada Serba Makna. Jakarta

Machfoedz. I, (2008). Menjaga Kesehatan Rumah dari Berbagai Penyakit. Yogyakarta: Penerbit Fitramaya

Notoadmodjo, S, (2008), Ilmu Kesehatan Masyarakat Prinsip-Prinsip Dasar. Rinika Cipta, Jakarta

Profil Puskesmas Durian Luncuk. (2018). Data Penyakit Wilayah Kerja Puskesmas Durian Luncuk Kabupaten Batanghari

Riyanto, A. (2011). Aplikasi Metodologi Penelitian Kesehatan. Yogyakarta : Nuha Medika

Rusdiyanti, I. (2013). Strategi Komunikasi Dan Tingkat Kepuasan (Studi Korelasional Pengaruh Strategi Komunikasi Petugas Askes Terhadap Tingkat Kepuasan Pasien Pengguna Kartu Askes di Bagian Rawat Inap RSUD Djoelham Binjai). Medan. https://jurnal.usu.ac.id/flow/article/view/16836. di akses tanggal 25 Septeber 2019

Sugiyono, (2013). Cara Mudah Menyusun Skripsi, tesis, dan Disertasi. Bandung

Susilo. W.H \& Limakrisna, N. (2012). Cermat Menyusun Kuesioner Penelitian Ilmu Keperawatan. Jakarta: Trans Info Medika

Tamsuri. A. (2009). Komunikasi Keperawatan. Jakarta

Wahyuni, C.U \& Artanti KD M. (2016). Jurnal Strategi Komunikasi dalam Pembinaan Agama pada Suku Anak Dalam Bukit Duobelas Kecamatan Pauh Kabupaten Sarulangun Provinsi Jambi. Di Unduh Bulan Agustus 2018

Wardani, dkk. (2008). Jurnal Perancangan Sistem Pelaporan Untuk Pemantauan Kasus Penyakit Menular Potensial Wabah Berbasis Jaringan Dengan Short Message Service (SMS). Continuing Medical And Health Education (CMHE). Prosiding Seminar Nasiona dst.

Zulkifli, (2008). Posyandu dan Kader Kesehatan.Di Unduh Bulan September 2018. 